\title{
Clairvaux Başrahibi Bernard'ın İkinci Haçlı Seferi Faaliyetleri ve Dönem Hırıstiyanlarının Müslüman Algısı
}

\section{The Second Crusade Activities of Abbot Bernard of Clairvaux and Muslim Sense of Christians of the Era}

\section{Özlem Genç* (i)}

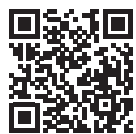

*Doç. Dr., Ondokuz Mayıs Üniversitesi, Fen-Edebiyat Fakültesi, Tarih Bölümü, Samsun, Türkiye

\section{ORCID: Ö.G. 0000-0002-2564-7447}

Sorumlu yazar/Corresponding author: Özlem Genç

Ondokuz Mayıs Üniversitesi, Fen-Edebiyat Fakültesi, Tarih Bölümü, Samsun, Türkiye

E-posta/E-mail: ozlmgnc@gmail.com

Başvuru/Submitted: 24.01 .2021 Revizyon Talebi/Revision Requested: 24.02.2021

Son Revizyon/Last Revision Received: 10.03.2021

Kabul/Accepted: 26.04 .2021

\section{Atıf/Citation:}

Genc, Ozlem. "Clairvaux Başrahibi Bernard'ın İkinci Haçıı Seferi Faaliyetleri ve Dönem Hırıstiyanlarının Müslüman Algısı." Tarih Dergisi Turkish Journal of History, 74 (2021): 67-81. https://doi.org/10.26650/iutd.867381

\section{öz}

XII. yüzyıl Batı Avrupa halkının geçen yüzyıla göre daha rahat yaşadıkları bir dönemdir ancak bu dönemde, İkinci ve Üçüncü Haçlı Seferleri de düzenlenmiştir. İkinci seferde etkin faaliyet yürüten kişi Clairvaux Manastırının Başrahibi Bernard'dır. Bernard, pek çok yere yazdığı mektuplar, verdiği vaazlar ile seferin oluşumuna ciddi katkı sağlamıştır. Mektuplarında Müslümanlar için kullandığı ifadeler dönem Hıristiyanlarının Müslüman algısını örnekler niteliktedir. Bu çalışmada Bernard`ın mektupları orijinal Latince metninden incelenmiş hem sefere etkileri, hem de dönem Hıristiyanlarının Müslüman algısı değerlendirilmeye çalışılmıştır.

Anahtar sözcükler: Orta Çağ, İkinci Haçlı Seferi, Clairvaux Başrahibi Bernard, Müslüman Algısı

\section{ABSTRACT}

The twelfth century is seen as an era in which people, compared to the century before, lived comfortably but in this era both Second and Third Crusades were organized. In the Second Crusade the active agent was Clairvaux Monastery's Abbot Bernard. Bernard made a serious contribution to the formation of the campaign with the letters he wrote to many places and the sermons he gave. The expressions he uses for Muslims in his letters are examples of the Muslim sense of Christians of the era. In this study, Bernard's letters were examined in the original Latin text, and both the effects of the campaign and the Muslim sense of Christians of the era were then evaluated.

Keywords: Middle Ages, Second Crusade, Abbot Bernard of Clairvaux, Muslim Sense 


\section{Extended Abstract}

The Crusades are among the most important events that characterize the Middle Ages. The period of the Crusades, which began in the eleventh century and ended with the loss of the lands that came into the hands of Christians a century later, covered 200 years in which Christians and Muslims interacted in every sense. As it concerned both the East and the West, it has been the subject of contemporary works both in Turkey and abroad many times, and numerous works have been written for each Crusade. To solve the problem of the Crusades, it is important to analyze the prominent figures of the Crusades and address these events with a systematic thinking style to classify information in the sources and achieve a result by considering the factors of these events. This is important in terms of accurate and objective evaluation, understanding and analysis, via scientific methods, of the mentality, that paved the way for these significant historical events. Accordingly, this study aimed to contribute to our knowledge on the Second Crusade by addressing Bernard's activities in particular and to understand the world of thought that drove these Crusades in general.

The formation of these quests that pushed thousands of people into the unknown voluntarily was as troublesome as the Crusades themselves and is worth understanding. In parallel to the emphasis on the element of religion, it is observed that those who undertake the said trouble were generally the clergymen. Perhaps the most well-known of these clergymen is Pierre L'Ermite, but he was not official because he did not take up this task at the will of the pope. The clergyman who fulfilled this requirement was Abbot Bernard of Clairvaux, who is the subject of our study. Consulted and asked for help in almost every issue, Bernard is also known as the person who advocated for Pope Innocent II against Pope Anacletus. He was supported by Emperor Lothair III in 1130 who helped him become the pope again, saving the Church from being tom apart. While Pope Eugene III, the pope of the period under discussion, was a student of his, King Louis VII of France ruled under his spiritual influence.

The twelfth century, during which Bernard lived and the Second and Third Crusades were waged, was generally a period of prosperity except for a few famines. Due to mass migration controlled by the military elite class, agriculture had started to attract more attention in the Europe of the eleventh century. The new technology used in tillage increased the yield markedly, and this development continued with the constant growth of the use of money and the market economy throughout the twelfth century. Towns expanded and many of them turned into trade centers. In most of the towns, cathedrals and pastor schools were established, and the sons of the nobility who preferred clergy life to military life were often accepted into these institutions. Such urban schools immediately overshadowed the priest schools, and the preference for this new type of school increased rapidly. 
The new monastic sects, especially the Cistercians, benefited from these developments: Since they looked for the condition of being at least 16 years old to enter the monastery, the monks had received intellectual training in these urban schools before entering the monastery, and this trend changed how the love of God was comprehended, making it possible to raise individuals who would join the Crusades. Close ties were established between the monasteries and the nobility of the military elite, and the monks were generally from this class and supported military campaigns with their prayers. In this respect, this can be seen as a period that allowed for the financial and mental formation of new campaigns.

The First Crusade, as it is known, was the only Crusade that provided the final and successful results, namely, that the Christians took Jerusalem and founded several small states within the Muslim geographical area. Since a good example was available before them, organizing a new Crusade would, of course, be less troublesome than the others, but the Second Crusade was to fail. As is well-known, the main reason for this Crusade's failure was the capture of Edessa by Muslims in 1144 and the termination of the Edessa Crusader County. The purpose of organizing the Crusade was the fear that Jerusalem would be lost as well, so the most influential clergyman of the period, Bernard and King Louis joined forces and sent a delegation to the pope; Bernard was assigned with this task by the pope, held meetings in several places and wrote letters for the organization of the Crusade.

The most widely used evidence by Bernard in his sermons was, of course, that the holy lands must be cleansed of heretics, the brothers of religion were persecuted and this Crusade was a necessity. In addition, the famine in 1146 was another factor that assisted Bernard's sermons. Bernard also mentioned in his sermons that the way to get rid of this disaster and to earn the love and mercy of God was to participate in the Crusade. He also wrote letters to many places. These letters gave information about the Muslim perception of the period and the status of Jerusalem as well as his efforts for the organization of the Crusade.

In general, both his sermons and the letters of Bernard of Clairvaux became successful. By this means, many people wanted to participate in the Second Crusade Regarding how he achieved this success, it is observed that he was first interested in the theory and claimed the Crusades to be a Righteous War, and he tried to base the justification on the Bible and the religious elders then trusted by the wider society. This effort of Bernard of Clairvaux is extremely important because those who would join the Crusade would have greater courage and desire when they learned the righteous justifications, and this was indeed the case. Although the campaign was unsuccessful, Bernard's activities had had an impact on the formation of the Crusade. 


\section{Giriş}

Haçlı Seferleri, Orta Çağ denince akla gelen ilk unsurlardandır. Hem Doğu hem de Batı'yı yakından ilgilendirmesi dolayısıyla gerek ülkemizde gerekse yurt dışında pek çok kez çağdaş eserlere konu edilmiş, her bir sefer için sayısız eser kaleme alınmıştır. Kabul edilecektir ki dinin itici unsur olarak kullanıldığı Orta Çağ’ın kaynaklarının tarafsız bir bakış açısıyla yazılması son derece zordur. Bu nedenle dönemin Hıristiyanlarının o çağdaki Müslümanlar hakkında ne düşündüğünü anlamak için ana kaynakları görmek son derece önemlidir. Farklı yorum ve perspektiflere dayalı bilgiler ihtiva ettikleri için sadece çağdaş kaynaklara bağlı kalarak konuyu ele almak, gerçeğin ortaya konması hususunda bizleri yanılgıya düşürecektir. $\mathrm{Bu}$ nedenle dönemin kaynaklarına başvurmak son derece ehemmiyet taşımaktadır. Haçlı Seferlerini daha iyi anlayabilmek için seferlerde öne çıkan şahısların incelenmesi de önem arz etmektedir. İşte bu çalışmayla özelde Bernard'ın faaliyetleri konu edilerek İkinci Haçlı Seferine dair bilgimize katkı sağlanması, genelde ise bu seferleri besleyen düşünce dünyasının anlaşılması hedeflenmektedir.

Çăgdaş eserlere dönecek olursak çoğunlukla askeri tarih formatında ele alınmış bu çalışmalarda seferlerin arka planına nadiren değinildiği görülmektedir. Başka bir ifadeyle Birinci Haçlı Seferi istisna olmak üzere diğer seferlerin yapılmasının nedenleri birkaç cümle ile özetlenmektedir. Oysa binlerce insanı gönüllü bir şekilde bilinmezliğe iten bu maceraların oluşum süreci en az seferlerin kendisi kadar zahmetli olmuştur ve anlaşılmaya değerdir. Seferlerin gerçekleştirilmesinde en çok din unsurunun kullanılmasına paralel olarak, söz konusu zahmeti üstlenenlerin genellikle din adamları olduğu görülmektedir. $\mathrm{Bu}$ din adamları arasında belki de en çok bilineni Pierre L'Ermite olmakla birlikte, bazı tarihçiler aksini düşünse de, bu görevi papanın isteğiyle üstlenmediği genel olarak kabul edildiği için, bir resmiyeti yoktur. İkinci seferde ise çalışmamıza konu ettiğimiz Clairvaux Başrahibi Bernard, bizzat papa tarafından Haçlı Seferini organize etmekle görevlendirilmiştir.

1090'da Kuzey Fransa'daki Fontaines'de doğan Bernard, 1113'te Citeaux'da keşiş, 1115 'te Clairvaux'da başrahip olmuştur. Bu dönemde yirmili yaşlarında oldukça genç birisidir'. 20 Ağustos 1153'te Burgondiya'daki manastırında ölen “kilise babalarının sonuncusu"² Bernard'ın ölüm tarihi hariç, hayatına dair diğer tüm tarihler tartışmalıdır. 40 yılını manastırda geçirdikten sonra, yaklaşık 63 yaşında ölmüş, 1174’te Papa III. Alexander tarafından azizlik mertebesine yükseltilmiş, 1830'da da Papa VIII. Pius tarafından "kilise doktoru” unvanına layık görülmüştür. Kendisi 19 yaşındayken³ ölen

G. R. Evans, Bernard of Clairvaux, Oxford University Press, 2000, s. 9.

Thomas Merton, The Last of the Fathers, A Harvest Book, 1882, s. 9.

J. M. B. Porter, "Bernard of Clairvaux and the Foundation of the Monastery of Clairvaux (1115)", Great Events in Religion, vol. 1, ed. F. Curta, A. Holt, ABC-Clio, CA 2017, s. 532. 
annesi, Burgondiya'nın güçlü soylu bir ailesinden gelmektedir ve Bernard hariç beş çocuğu olmuştur ${ }^{4}$.

Hemen her meselede kendisine danışılan ve yardım istenen Bernard, 1130'da İmparator III. Lothar tarafından desteklenen Papa Anacletus'a karşı II. Innocentius'u destekleyerek onun tekrar papa olmasını sağlayan ve kiliseyi parçalanmaktan kurtaran kişi olarak da bilinmektedir. Dönemin papası III. Eugenius onun öğrencilerindendir, Fransa kralı VII. Louis de onun manevi etkisi altına girmiş bir liderdir5.

\section{Yeni Seferi Mümkün Kılan Gelişmeler ve Zihinsel Altyapının Oluşumu}

Bernard'ın yaşadığı, İkinci ve Üçüncü Haçlı Seferlerinin yapıldığı XII. yüzyıl, yaşanan birkaç kıtlık sayılmazsa, refah dönemidir. XI. yüzyılda Avrupa'da tarıma daha çok dikkat edilmeye başlanmıştır. Toprak işlemede kullanılan yeni teknoloji verimi artırmış, bu gelişme XII. yüzyıl boyunca para ve pazar ekonomisinin sürekli büyümesiyle sonuçlanmıştır. Kasabalar da gelişmiş, pek çoğu ticaret merkezi olmuştur. Kasabaların büyük bir kısmında katedral ve papaz okulları kurulmuş, bunlar askeri hayata karşı ruhban hayatı tercih eden soyluların erkek çocukları tarafından doldurulmuştur.

Yeni manastır tarikatları, özellikle Cistercianlar, bu gelişmelerden yararlanmışlardır: Manastıra giriş için en az 16 yaşında olma şartı aradıklarından, keşişler manastıra girmeden önce bu okullarda eğitim almışlar, bu eğilim Haçlı Seferine katılacak zihniyette bireylerin yetişmesini sağlamıştır. Manastırlar ve askeri sınıfı oluşturan soylular arasında yakın bağlar kurulmuş, keşişler genellikle bu sınıftan çıkarken, dualarıyla askeri seferleri desteklemişlerdir. $\mathrm{Bu}$ açıdan devir, yeni seferlerin mali ve zihni oluşum imkânlarını veren bir dönem olarak görülebilir.

XI. yüzyılda Benedikten tarikatını benimseyen daha katı manastırların kuruluşu ${ }^{6}$, XII. yüzyılın dini tutumunu da etkilemiş, bu katı dini eğilim Müslüman algısında da kendini göstermiştir. Bunun en iyi örnekleri özellikle ruhban sınıfa mensup kişilerin eserlerinde Müslümanlarla ilgili değişik ifadeler kullanılmasıyla karşımıza çıkmaktadır. Bunlardan biri de Clairvaux Başrahibi Bernard'dır.

\section{Bernard'ın Haçlı Faaliyetleri}

Bilindiği üzere, Birinci Haçlı Seferi başarı ile sonuçlanan tek sefer olmuş, Hıristiyanlar Kudüs’ü ele geçirmiş ve Müslüman coğrafyada birkaç siyasi oluşum meydana getirmişlerdir. Önlerinde iyi bir örnek olduğundan yeni bir sefer düzenlemek elbette diğerlerine göre daha

4 Brian Patrick McGuire, "Bernard's Life and Works: A Review”, A Companion to Bernard of Clairvaux, ed. B. P. McGuire, BRILL, 2011, s. 22.

5 Ebru Altan, İkinci Haçlı Seferi, TTK, Ankara 2003, s. 16.

6 Adrian H. Bredero, Bernard of Clairvaux, Wm. B. Eerdmans Publishing, 1996, s. 9-11. 
az zahmetli olacak, ancak İkinci Haçlı Seferi başarısızlıkla sonuçlanacaktır. Bu seferin ana sebebi, malum olduğu üzere, 1144’te Müslümanlar tarafından Urfa'nın ele geçirilmesi ve Urfa Haçlı Kontluğu'na son verilmesidir. Peki, yüz binler bu sefere sadece ilk seferin başarısı motivasyonu ile mi çıktılar? Bunun, tarihi açıdan çok önemli olmakla birlikte, onca insanı yollara düşürmeye tek başına yeterli olamayacağı açıktır. Aksi halde gerek Bernard gerekse papanın vaazlarında ya da mektuplarında Urfa'dan da bahsetmeleri gerekirdi, oysa böyle bir kayıt yoktur. Seferin düzenlenmesinin amacı Kudüs'ün de kaybedileceğinden korkulmasıdır bu nedenledir ki dönemin en sözü geçen din adamı Bernard ve Kral Louis bir olarak papaya heyet göndermişler ${ }^{7}$, Bernard papa tarafindan bu işle görevlendirilmiş, pek çok yerde toplantılar yapmış ve seferin düzenlenmesine yönelik mektuplar yazmıştır. Bernard'ın Speyer halkına ve ruhban sınıfına, Doğu Francia halkına ve ruhbanlarına, Bavyera'ya, İngiltere halkına, Köln başpiskoposu Arnold'a, Brescia piskoposu Manfred'e, Flanders'a, Bohemya düküne yazdığı mektupların içerikleri bilinmekle birlikte daha pek çok mektubunun da kayıp olduğu düşünülmektedir ${ }^{8}$.

Bernard'ın eserlerinin ya da mektuplarının seferler açısından bir diğer önemi de Haklı Savaş teorisini vurgulamasıdır. O, Haçlı Seferlerini savunmak için teorinin dayandırıldı̆̆ Augustinus'un ilkelerini kullanmıştır. İlk olarak bir Haçlı Seferi, adaletsizliğe, Tanrı'ya ve onun kilisesine, inançsızlar tarafından yapılan adaletsizliğe karşı bir mücadeledir. İkincisi, Haçlılar, yeryüzünde Tanrı'nın vekili olan papa aracılığıyla, Tanrı'nın emriyle savaşırlar' ${ }^{9}$ Bu iki nedenden dolayı seferlerin düzenlenmesi haklıdır. Haçlı Seferi Haklı Savaş’tır. Bu anlayış Haçlı Seferlerindeki dini hissiyatın yanına, hukuki bir sebep de eklendiğini göstermektedir.

Bernard'ın öncelikli faaliyeti, bu seferlere katılım noktasında uzun yollar aşarak pek çok yerde çağrıda bulunmuş olmasıdır. Bu yolda, Haçlı Seferine katılım sağlanması ve dua amacıyla gittiği yerlerin listesi de oldukça kabarıktır. Speyer, Worms, Kreuznach, Pichenbach, Coblenz, Remagen, Köln, Brauweiler manastırı, Aachen, Maastricht, Liege, Huy, Gembloux, Villers, Fontaine-l'Eveque, Binche, Mons, Valenciennes, Cambrai, Vaucelles, Gomme, Humbleux manastırı, Laon St. John manastırı, Rheims, Chalons-sur-Marne ${ }^{10}$, Flanders, Arras, St. Bertin, St. Omer, Bruges, Afflighem, Mainz, Kenzingen, Freiburg, Basel, Constance ${ }^{11}$ ve Schaffhausen ${ }^{12}$ bunlardan bazılarıdır. Yedi ay manastırdan uzak kalan Bernard, binlerce mil yol kat etmiş, Haçlı Seferinin sebepleriyle ilgili düzinelerce vaaz vermiştir ${ }^{13}$.

\footnotetext{
$7 \quad$ Altan, a.g.e., s. 16.

8 Jonathan Philips, The Second Crusade, Yale University Press, London 2007, s. 69-70.

9 Marlow Gazzoli, "St. Bernard and The Theology of Crusades”, https://thejosias.com/2015/03/17/st-bernardand-the-theology-of-crusade/16.01.2018.

10 Philips, a.g.e., s. 96-97.

11 Watkin Williams Wynn, Saint Bernard of Clairvaux, Manchester University Press, 1935, s. 269-276.

12 Conor Kostick, "Social Unrest and the Failure of Conrad III's March Through Anatolia, 1147", German History, XXVIII/2, Oxford University Press, 2010, s. 126.

13 Philips, a.g.e., s. 97.
} 
Verdiği vaazlarda en çok vurguladığı hususlar elbette kutsal toprakların kâfirlerden temizlenmesi, din kardeşlerinin zulüm gördüğ̈̈ ve bu seferin bir gereklilik olduğudur. Bunların yanında, 1146 yılında yaşanan kıtlık da Bernard'ın vaazlarına yardımcı olan bir diğer etkendir. Dönem yıllıklarının -Lotharingia başta olmak üzere- neredeyse hepsi, alanı oldukça geniş, daha önce hiç duyulmamış ölçüde ağır bir kıtlık yaşandığını, tahıl fiyatlarının 20-25 kat arttığını bildirmektedirler ${ }^{14}$. Bernard verdiği vaazlarda bu felaketten kurtulmanın, Tanrı'nın sevgi ve merhametini kazanmanın yolunun sefere katılmaktan geçtiğine de değinmiştir ${ }^{15}$.

Ayrıca o dönemde Müslümanların Hıristiyanlara nasıl davrandıklarıyla ilgili Batı'ya aksettirilen bilgiler de seferin oluşmasına katkı sağlamıştır. Bu bağlamda Bernard'ın sekreterliğini yapmış olan Nicholas'ın 1126'da Bernard'a yazdığı mektupta kullandığı ifadeler konuyu örnekler niteliktedir:

Hıristiyan halkın bir kısmı zincire vuruluyor, bir kısmı da katliama uğramış kuzular gibi kesiliyorlar $^{16}$.

Doctor mellifluus (tatlı dilli âlim/öğretmen) ${ }^{17}$ lakaplı Bernard sefer için yola çıkan orduları korumak için de girişimlerde bulunmuş, sefere gidenlerin asıl hedefe güvenle ulaşmasını sağlamaya çalışmıştır. Bu amaçla Bernard, o dönemde kuzey ve kuzeydoğuda tehdit oluşturan Slav Wendlere karşı, Moravyalılar, Saksonlar ve Danimarkalılara, Alman İmparatoru Konrad, yüksek rütbeli din adamları ve prensler adına mektuplar göndermiş, özellikle Moravyalılara yazdığında, 11-23 Mart'ta Frankfurt'ta toplanan, Bernard'ın da katıldığı meclisin aldığ kararları ve Magdeburg'da toplanacak meclise katılmaları gerektiğini bildirmiş, tüm Hıristiyanları kutsal topraklara yapılacak sefere davet etmiştir ${ }^{18}$. Bu mektupların amacı

14 Annales Stederburgenses: Büyük kıtlık oldu (fames magna fuit), ed. M. G. Pertz, Annales Stederburgenses, MGH, SS XVI, Hannover 1859, s. 207. Annales Rodenses: O y1l çok kötü kıtlık oldu (eodem anno facta est fames vehementissima), ed. M. G. Pertz, Annales Rodenses, MGH, SS XVI, Hannover 1859, s. 719. Annales Remenses et Colonienses: Büyük kıtlık oldu (fames maxima fuit), ed. M. G. Pertz, Annales Remenses et Colonienses, MGH, SS XVI, Hannover 1859, s. 733. Annales Brunwilarenses: Bu y1l tüm dünyada büyük bir kıtlık oldu (hoc anno in tantum angustia famis per totum orbem prevaluit), ed. M. G. Pertz, Annales Brunwilarenses, MGH, SS XVI, Hannover 1859, s. 727. Annales Aquenses: Daha önce duyulmamış kadar büyük bir kıtlık oldu, Aachen tahılının modiusu (9 litrelik ölçü birimi) 25 solidusa satıldı (fames maxima, et quod inauditum ante fuerat, modius Aquensis tritici venditur), ed. M. G. Pertz, Annales Aquenses, $M G H$, SS XVI, Hannover 1859, s. 686. Annales S. Iacobi Leodiensis: Duyulmamış bir kıtlık oldu, kış buğdayının modiusu 20, kabuklu buğdayınki 11 solidustan zorla kendini telafi etti (fames inaudita, modio siliginiz viginti, speltae undecim solidis vix se redimentibus), ed. M. G. Pertz, Annales S. Iacobi Leodiensis, MGH, SS XVI, Hannover 1859, s. 641. Kıyaslama yapabilmek için: 1085'ten önce İspanya'da buğdayın 1 modiusu 1 solidus etmektedir. Thomas F. Glick, Islamic and Christian Spain in the Early Middle Ages, BRILL, 2005, s. 108.

15 Kostick, a.g.e., s. 127.

16 "Populi christiani partim conjiciuntur in vincula, partim trucidantur sicut oves occisionis", ed. J. P. Migne, Bernardus Claraevallensis Abbas Epistolae, Epistolae Appendix, Patrologia Latina, vol. 182, Montrouge 1854, s. 671.

17 Burnam W. Reynolds, The Prehistory of the Crusades, Bloomsbury Publishing, 2016, s. 16.

18 “...qui nimirum omnes in festo apostolorum Petri et Pauli aput Magdeburg conuenire debent.", No: 274, ed. Antonin Bocek, Codex Diplomaticus et Epistolaris Moraviae, vol. I, Olomucii 1836, s. 255; Migne, a.g.e., s. 651-2. 1147'de yazılmıştır. 
Elbe'nin ötesinde yaşayan ve endişe kaynağı olan Slav kavimlerinin, Haçlı ordularının Bizans topraklarına doğru ilerleyişi sırasında onlara yan taraflarından saldırmaları ihtimalidir ${ }^{19}$. Bu nedenle Saksonlar, Danimarkalılar ve Moravyalılar, Wendlerle mücadele etmeleri için Haçlı Seferine katılmaktan men edilmişler, kendilerine Slavlarla mücadelenin de bir Haçlı Seferi olduğu söylenmiştir. Bernard başka bir örnekte ise Bohemyalılara sefere katılmaları için davet mektubu göndermiştir ${ }^{20}$.

Bu noktada Bernard'ın sefer çağrısı yaparken hiçbir zorlukla karşılaşmadığı düşünülmemelidir. Bunun örneklerini yine mektuplarında görmek mümkündür. En iyi örnek Nevers kontesi Carinthialı Ida’ya yazdıklarıdır:

Saygıdeğer Vezelay Başrahibi, sizin ve halkınızın, tacirleri ve Vezelay'e $e^{21}$ gitmek isteyen tüm insanları engellediğinizi şikâyet etti... Uyarıyoruz ve istiyoruz ki bundan sonra herhangi bir şekilde bunu yapmayın. Korkuyoruz, eğer böyle şeyler yapmaya başlarsanız, burada size ve bulunduğu yerde de kocanıza çok zarar verebilirler ki biz bunu kesinlikle istemeyiz. Bize inanını ve bu kötülükten tamamen vazgeçiniz ${ }^{22}$.

Bahsi geçen konu dönemin papası III. Eugenius tarafından da önemsenmiş ve bu hususta aynı kişiye bir mektup da papa tarafından yazılmıştır:

Hatırası hayırla anılan Kont William'in, ne onun ne de ülkesindeki adamlarının, tüccarların ve gitmek isteyen diğerlerinin Vezelay'e gitmesine engel olmayacağına dair, saygıdeğer biraderimiz Auxerrelı Hugh ve inançlı evladımız Clairvaux Başrahibi Bernard huzurunda söz verdiği söyleniyor. Şimdi ise inançlı evladımız Vezelay Başrahibi Pontius 'tan ögrendiğimize göre, buraya gitmek isteyenleri kendin ya da adamların aracıliğıyla engelliyor ve rahatsiz ediyorsun. Bu nedenle, mevcut metinle, bu insanllk dişı eylemi bir daha yapmaya cüret etmemeni zatına emrediyoruz. Bunu yapmaya cüret edersen, Rabb'i çok seven Azize Mary'nin duacıları vasitasiyla, her şeye gücü yeten Tanri 'nın öfkesine maruz kalmaktan korkmalısın ${ }^{23}$.

19 Wynn, a.g.e., s. 279.

20 No: 275; Bocek, a.g.e., s. 255; Migne a.g.e., s. 652. 1147'de yazılmıştır.

21 Vezelay'de 31 Mart 1146'da büyük meclis toplanmıştır.

22 "Conqueritur venerabilis abbas Vizeliacensis, quod vos, et clientes vestri, mercatores et caeteros Vizeliacum volentes ire prohibetis: .....; monemus et rogamus, ne id deinceps ullo modo faciatis. Timemus enim, si talia facere coeperitis, ne forte et vobis hic, et viro vestro, ubi ipse est, plurimum possint obesse, quod omnino nollemus. Credite ergo nobis, et omnino desistite a malitia hac.” No: 375, ed. Curis D. Joannis Mabillon, Sancti Bernardi, De Laude Novae Militiae, cap. I, Opera Omnia, Tomus I-II, Paris 1839, s. 679-680. 1148'de yazılmıştır.

23 "Guillelmus comes bonae memoriae in praesentia venerabilis fratris nostri Hugonis Antissiod. et dilecti filii nostri Bernardi abbatis Claraeval. dicitur promisisse, quod mercatores et caeteros Vizeliacum ire volentes, neque ipse, neque suae terrae homines prohiberent. Nunc vero, sicut dilecti filii nostri Pontii Vizeliacensis abbatis relatione accepimus, ire illuc volentes per te, et per tuos homines prohibes et infestas. Ideoque nobilitati tuae per praesentia scripta mandamus, quatenus inhumanitatem hanc facere de caetero non praesumas. Quod si facere praesumpseris, timendum tibi est ne indignationem omnipotentis Dei, beatae Mariae precibus, quae multum dilexit Dominum, consequaris.” Migne, a.g.e., s. 1323. 3 Nisan 1148 'de yazılmıştır. 
Bernard'ın, Haçlı Seferleri ile ilgili yaptığı çalışmalar arasında Tapınak Şövalyelerinin ${ }^{24}$ kurucularından (grand master) Paynsli Hugh’un isteğiyle yazdığı Yeni Şövalyeliğin Övgüsü (De Laude Novae Militiae) adlı eser de bulunmaktadır. Hugh, Bernard'dan şövalyeler için bir şey yazmasını istemiştir. Bernard, Tapınak Şövalyelerinin durumunu Hıristiyan inancındaki bonum certamen (yüce mücadele) ile kimlikleştirmiş, Hugh'a kurtuluş kapısını açarken İncil'deki Timoteos 2: 4,7'e atıfta bulunmuştur: yüce mücadeleyi sürdürdüm (bonum certamen certavi). Hugh'u İsa'nın askeri olarak tanımlayan yazar, böylece eserin daha başında Haklı Savaşın iki ilkesini vermiştir. Ona göre Tapınakçıların mücadelesi İsa'nın mücadelesidir, onlar İsa'nın askerleridir ${ }^{25}$. Bernard'ın Tapınak Şövalyelerine verdiği önem seferin öncesinde ve sonrasında gerek Kudüs kraliçesine gerekse Kudüs patriğine yazdığı himaye ve tavsiye mektuplarından da anlaşılmaktadır. Tarihsel sıralamayla vermek gerekirse Kudüs patriğine şunları yazmıştır:

Rica ediyorum gözleriniz Tapınak Şövalyelerinin üzerinde olsun, kilisenin böylesine istekli savunucularına büyük bir özenle içinizi açını. Canlarını kardeşleri uğruna ortaya koyan bu kişileri desteklerseniz, hem Tanri yı hem insanları memnun eden bir şey yapmış olacaksiniz ${ }^{26}$.

Bernard'ın Kraliçeye yazdığg üç ayrı tavsiye mektubunda ise şu ifadelere yer verilmektedir:

Size başkalarını tavsiye etmeye nasıl cüret ettiğimi görüyorsunuz, bu nedenle bu premonstratensian biraderleri ${ }^{27}$ cesaretten ziyade belki de boşuna tavsiye edebilirim. Aslında onlar kendi meziyetleriyle öylesine tavsiye edilebilirler ki başkasına ihtiyaç duymazlar. Hata yapmiyorsam, konsil üyesi, ateşli bir ruha sahip, karmaşa durumunda sabırlı, konuşma ve eylem sırasında güçlü bulunacaklar. Kendilerini, ete ve kana karşı değil, göklerdeki kötülüğün gücüne karşı, Tanrı ’nın zırhı ve Tanri `nın kelamı olan Kutsal Ruh'un kılıcıyla kuşattılar. Onları barışçıl savaş̧̧ılar, insanlara zararsızlar, şeytanlara acımasızlar olarak kabul ediniz, ya da onların hactlıklarının sebebi olan Mesih $i$ kabul ediniz $z^{28}$.

Çok değerli dayım Andreas, ona her konuda inanabiliyoruz, yazısında bize çok iyi şeyler

24 Tapınak Şövalyeleri’nin İkinci Haçlı Seferi`ndeki faaliyetleri için bkz. Muhittin Çeken, Tapınak Şövalyeleri, Timaş Yayınları, İstanbul 2020.

25 Gazzoli, https://thejosias.com/2015/03/17/st-bernard-and-the-theology-of-crusade/.

26 "Super milites Templi ponite, quaeso, oculos vestros, et tantae pietatis viscera tam strenuis Ecclesiae propugnatoribus aperite. Hoc siquidem acceptum erit Deo et gratum hominibus, si fovetis eos, qui suas animas pro fratribus posuerunt." No:175, Mabillon, a.g.e., s. 394.

27 Kudüs'e hac için gitmektedirler.

28 "Videtis quantum praesumam de vobis, cui audeo et alios commendare. Quanquam Praemonstratenses fratres istos magis fotassis superflue commendarim, quam temerarie. Sunt merito ita commendabiles suo, ut non egeant alieno. Invenientur, nisi fallor, viri consili, spiritu ferventes, in tribulatione patientes, potentes in opere et sermone. Induerunt se armatura Dei; et gladio spiritus, quod est verbum Dei, sese accinxerunt, non adversus carnem et sanguinem, sed contra spiritualia nequitiae in caelestibus. Suscipite illos, tanquam bellatores pacificos, mansuetos ad homines, violentos ad daemones. Imo Christum in eis suscipite, qui est causa peregrinationis eorum." No:355, Mabillon, a.g.e., s. 651. 1142'de yazılmıştır. 
gösterdi: sizin Tapınak Şövalyelerini sevdiğinizi ve kendinize yakın tuttuğunuzu, bölgenin tehditkâr tehlikelerine, Tanrı tarafindan size verilmiş bilgelik uyarınca, yararl fikirler ve yardımlarla să̆duyulu ve bilgece katlandı̆̆ınızı söyledi ${ }^{29}$.

Sizin nazarınızda iyi bir yere sahip olduğumu duyan adamlar ve Kudüs ’e gidecek olan pek çok kişi, mükemmel olan size, benim aracılı̆̆ımla tavsiye edilmek istiyorlar. Onlardan biri benim akrabam olan bu gençtir. Kollarının güçlü kuvvetli, ahlaki bakımdan da yumuşak başlı olduğu söylenir. Bu zamanda dünyadan çok Tanrı için savaşmayı seçtiğine memnunum. Bu nedenle alışık olduğunuzu yapınız ve hatırım için, tıpkı benim vasıtamla tanıyabildiğiniz geri kalan tüm akrabalarıma sahip çıktığınız gibi, bu da iyi bir şekilde sonuçlansın. Geri kalanlara gelince, şehvet isteği ve geçici şöhret sizi, cennetin krallı̆̆ına yolculuktan alıkoymasın. Yeryüzünde pek az gün yönetmek ve cennetin sonsuz krallı̆̆ından mahrum bırakılmak neden daha iyi olsun? Ama Rabb'e güveniyorum, siz daha iyi olacaksınız. Ĕger benim çok değerli dayım Andreas tarafindan sunulan tanıklık doğruysa, ki pek çoğumuz ona inanıyoruz, Tanri 'nın inayetiyle sonsuza kadar yöneteceksiniz. Hacılara, yoksullara ve özellikle mahsur kalmışlara özen gösteriniz, çünkü Tanrı, böyle kurbanlarla kazanılır.

Sizin iyi işlerle meşgul ve güvenilir olduğunuzu biliyorsak da, size zarar vermeyeceği ve bize yararı olacă̆ için bize sıklıkla yazınız ${ }^{30}$.

Görüleceği üzere Bernard, bir yandan dönemin şartlarından yararlanarak Haçlı Seferi zeminini oluştururken, öte yandan bu yoldaki engelleri ortadan kaldırmaya çalışmıştır.

\section{Müslüman Algısı}

Bernard'ın mektupları seferin yapılabilmesi için gösterdiği çabanın yanı sıra, dönemin Müslüman algısı ve Kudüs'ün durumuyla ilgili de bilgiler vermektedir. Orta Çağ’da Hıristiyanların Müslümanları nasıl gördüğü ve nasıl hisler beslediği pek çok çalışmaya konu edilmiştir. Bernard'ın mektuplarında geçen ifadeler de bu hisleri özetler niteliktedir.

29 “... Andreas clarissimus avunculus meus, cui in nullo decredere possumus, scripto suo nobis significans meliora: ...; fratres de Templo diligas, et familiares habeas; periculis imminentibus terrae, secundum sapientiam tibi a Deo datam, salutaribus consiliis et auxiliis provide et sapienter occurras." No: 289, Mabillon, a.g.e., s. 574575. 1153 'te yazılmıştır.

30 "Audierunt homines, quod locum gratiae habeam apud vos: et multi profecturi Jerosolymam petunt se vestrae Excellentiae per me commendari. Ex quibus est iste juvenis consanguineus meus, juvenis, ut aiunt, strenuus in armis, suavis in moribus. Et gaudeo quod ad tempus elegit militare Deo magis quam saeculo. Itaque facite morem vestrum, et bene sit huic propter me; sicut caeteris omnibus propinquis meis fuit, qui per me vobis innotescere potuerunt. De caetero cavete, ne voluptas carnis et gloria temporalis impediant vobis iter regni coelestis. Nam quid prodest paucis diebus regnare super terram, et regno coelorum aeterno privari? Sed confido in domino, quod melius facietis: et si verum est testimonium quod de vobis perhibet charissimus avunculus meus Andreas, cui multum credimus; et hic, et in aeternum Deo miserante regnabitis. Peregrinis, egenis, et maxime inclusis curam impendite: quia talibus hostiis promeretur Deus. Scribite nobis frequentius: quia et vobis non oberit, et nobis proderit, si esse vestrum, et bona studia plenius certiusque noverimus." No: 206, Mabillon, a.g.e., s. 434-435. 1156'dan önce yazılmıştır. 
Haçlı Seferlerinden önce malum olduğu üzere, Batı'da İslamiyet için "büyük düşman" imajı yaratılmaya çalışılmıştır. Bu noktada Muhammed ismi karanlıklar prensi Mahound haline dönüştürülmüş ${ }^{31}$, bu haliyle Orta Çağ roman ve oyun yazarlarının eserlerinde kelime oyunu olarak yer almıştır ${ }^{32}$. Bernard da buna benzer bir kelime oyunu kullanarak, Hz. İsa'nın karanlığın prensleri ile mücadele için kutsal topraklara geldiğini, Haçlı Seferleri ile gelenlerin ise aynı prenslerin takipçileri olan Müslümanlarla mücadele ettiğini ${ }^{33}$ belirtmektedir. $\mathrm{Bu}$ düşüncesini, Müslümanları "aynı kişilerin hizmetkârları” (ipsorum satellites) diye adlandırarak yazıya dökmüştür. Kullandığı ifadeler Tapınak Şövalyeleri üzerine yazdığı eserinde açıkça görülmektedir:

O (Hz. Ísa), o zamanlar, karanliğın prenslerini kendi gücüyle nasıl perişan ettiyse, burada da şimdi onların takipçilerini, imansızlı̆ı̆n evlatlarını, cesur adamlarının gücü̈le dăğtarak silip yok ediyor ${ }^{34}$.

Diğer bir örnekte Bernard, Doğu Francia ruhban sınıfına ve halkına yazdığı mektubunda Kutsal Kitab'a atıfta bulunup, Müslümanların haksız yere kutsal toprakları ellerinde tuttuklarını kastederek köpek ve domuz kelimelerini kullanmaktadır:

Yeryüzü çalkalandı; çünkü gökyüzünün Tanrısı kendi ülkesini kaybetmeye başladı... Burada 30 yıldan fazla insanlarla insan olarak yaşadl; kendisini de mucizeleri de orada gösterdi; kanını oraya adadı... Ve şimdi bizim günahlarımız yüzünden, kılıçla sözün ülkesini ${ }^{35}$ yıkanlar haç düşmanlı̆̆ının günahkâr başını kaldırdılar. Hatta bunu durduracak birisi çıkmazsa, yaşayan Tanri 'nın şehrini istila etmeleri, kurtuluşumuzun mekânlarını yıkmaları, mor kanla lekesiz Kuzu `nun ${ }^{36}$ kutsal yerlerini kirletmeleri yakındır. Dinsiz bir ağızla Hıristiyan dininin mabedine göz dikiyorlar ve seçilmiş yeri istila etmeye ve ayakları altında ezmeye teşebbüs ediyorlar ${ }^{37}$.

Ne yapıyorsunuz cesur adamlar, ne yapıyorsunuz haçın hizmetkârları? Kutsal olanı köpeklere ve incileri domuzlara ${ }^{38}$ böyle mi veriyorsunuz. Kâfirlerin pisliği ataların

31 Mohammad Talaat Ghunaimi, The Muslim Conception of International Law and the Western Approach, Martinus Nijhoff/The Hague, 1968, s. 3.

32 Özcan Hıdır, Batı `da Hz. Muhammed İmajı, İnsan Yayınları, İstanbul 2019, s.no.y.

33 Gazzoli, https://thejosias.com/2015/03/17/st-bernard-and-the-theology-of-crusade/.

34 "ut unde tunc in fortitudine manus suae tenebrarum principes exturbavit, inde et modo ipsorum satellites, filios diffidentiae, in manu fortium suorum dissipatos exterminet." Mabillon, a.g.e., s. 1253-4. Eser XII. yüzyılda yazılmakla birlikte tam tarihi bilinmemektedir.

35 Başlangıçta Tanrı ’nın din adamlarına ve onların torunlarına söz verdiği Filistin'i işaret eden "terra promissinis" ifadesi, son olarak ilahi Kudüs için kullanılmaktadır. Rudolf Kaschewsky, "The Image of Tibet in the West Before the Nineteenth Century", Imagining Tibet, ed. T. Dodin, H. Räther, Wisdom Publications, 2001, s. 7.

36 Hz. İsa kastedilmektedir.

37 “.....contremuit terra, quia coepit Deus caeli perdere terram suam...et annis plusquam triginta homo cum hominibus conversatus: suam utique, quam illustravit miraculis, quam dedicavit sanguine proprio... Et nunc peccatis nostris exigentibus, crucis adversarii caput extulerunt sacrilegum, depopulantes in ore gladii terram promissionis. Prope enim est, si non fuerit qui resistat, ut in ipsam Dei viventis irruant civitatem, ut polluant loca sancta, Agni immaculati purpurata cruore. Ad ipsum...religionis christianae sacrarium inhiant ore sacrilego, lectumque ipsum invadere et conculcare conantur.” No: 363, Mabillon, a.g.e., s. 661.

38 Matta 7/6: Kutsal olanı ne köpeklere atın, ne de incilerinizi domuzların önüne serin. Yoksa onları ayakları altında çiğnedikten sonra geri dönüp sizi parçalarlar. 
kılıçlarıyla temizlendikten sonra, ne kadar çok günahkâr burada günahlarını gözyaşlarıyla itiraf ederek af elde etti $!^{39}$

Bernard'ın Tapınak Şövalyesi olan dayısı Andreas'a yazdığı mektup ise seferden sonra yaşananları, Kudüs `teki durumu yansıtmaktadır:

.... (mektubunda) Rabb'in ${ }^{40}$ varliğıyla onurlandırdiğg toprağın, kendi kanıyla kurduğu şehrin tehlikede olmasından dolayı duyduğun korkuyu okudum. Yazı liderlerimize. Rabb'in toprağında iyi hiçbir şey yapmadılar. Çabucak geri döndükleri kendi topraklarında inanılamaz kötülükler yapıyorlar..... Yine de Rabb'in kendi halkını reddetmeyeceğine, kendi mirasını yüzüstü bırakmayacağına inanıyoruz... Gelmeni istiyorum ve gelmemenden korkuyorum. Ístemek ve istememek arasinda öyle bir yerdeyim ki, ikisini de hissediyorum ve neyi seçeceğimi bilmiyorum ${ }^{41}$.

Nihai olarak Müslümanlara dair kötü bir algı oluşturmaya çalışan Bernard, bunca kötülükle savaşmanın haklı bir savaş olacağını Hz. İsa'nın askerlerine bildirmektedir. Bu sözlerin sahibinin papanın görevlendirdiği resmi bir din adamı olduğu düşünüldüğünde, yaklaşımının bir şahsın kişisel tercihleri olmanın ötesinde bir mana taşıyacağı dikkate alınmalı, sıradan bir Haçlının dünyasında, gerçeğini bilmediği bir dünya için nasıl bir şevk oluşturacağı da hesaba katılmalıdır.

\section{Değerlendirme}

Başarılı ilk seferden yaklaşık yarım asır sonra Urfa'nın kaybıyla yeniden harekete geçirilen Haçlı orduları Doğu'ya yaptıkları bu yolculukta istediklerine ulaşamamışlardır. Sefere çıkmalarının ya da başarısızlıklarının sebepleri herkesçe malum olmakla birlikte seferin hazırlık sürecinde yaşananlara bakıldığında, yine derin bir dini propaganda ile karşılaşılmaktadır.

İkinci Haçlı Seferinin dini ayağını, Papa III. Eugenius’un görevlendirmesiyle üstlenen kişi Clairvaux Başrahibi Bernard olmuştur. XII. yüzyıl gibi derin bir dini taassubun yaşandığı dönemde en sözü geçen din adamı olmayı başaran yazar/azizle ilgili her eserde verilen bilgi Alman Kralı Konrad'ı sefer için ikna etmesi ve 1146'da Vezelay'de toplanan halka önceden hazırlanan haçlar yetmediği için elbisesini parçalayıp haçlar yaptırması ile

39 "Quid facitis, viri fortes? quid facitis, servi crucis? Itane dabitis sanctum canibus, et margaritas porcis? Quam multi illic peccatores, confitentes peccata sua cum lacrymis, veniam obtinuerunt, postquam patrum gladiis eliminata est spurcitia Paganorum!", No: 363, Mabillon, a.g.e., s. 661. 1146'da yazılmıştır.

40 Latince "dominus" kelimesi pek çok anlama gelmekle birlikte, dini açıdan bakıldığında Türkçe metinlerde "Rab" ile karşılanan Hz. İsa'ya işaret etmektedir.

41 "...legi et metum tuum pro periculo terrae, quam Dominus sua praesentia honoravit; periculo civitatis, quam suo sanguine daeicavit. Vae principibus nostis. In terra domini nihil boni fecerunt: in suis, ad quas velociter redierunt, incredibilem exercent malitiam,... Confidimus autem quia non repellet Dominus plebem suam, et haereditatem suam non derelinquet... Et cupio ut venias, et timeo ne venias. Ita inter velle et nolle positus, coarctor e duobus; et quid eligam, ignoro.” No: 288, Mabillon, a.g.e., s. 573. 1153 'te yazılmıştır. 
sınırlıdır. Oysa günümüze gelen eserleri ve mektupları incelendiğinde Haçlı düşüncesine, seferin hazırlanmasına, seferlerin lokomotifi olan Tapınak Şövalyelerine ne gibi katkılarda bulunduğu rahatlıkla görülmektedir. Faaliyetlerinde başarılı olduğu Papa III. Eugenius'a 1146'da yazdığı bir mektubundaki şu ifadelerle açığa çıkmaktadır:

Vaaz verdiğim ve bulunduğum yerlerde sayı artı̧ gösterdi. Kaleler ve şehirler boşaltıldı, artık yedi kadına bir erkek düşüyor, her yerde, kocaları yaşayan dullar var ${ }^{42}$.

Bu başarıyı nasıl sağladığına bakıldığında ilk olarak, teori kısmıyla ilgilendiği ve seferlerin haklı bir savaş olduğunu iddia ederek bunun gerekçelerini Kutsal Kitap’1 ve toplumun inandığı din büyüklerini temel alarak kanıtlamaya çalıştığı görülmektedir. Bu çaba son derece önemlidir; zira sefere katılacak kişiler haklı gerekçeleri öğrendiklerinde cesaretleri de istekleri de artacaktır. Nitekim öyle de olmuştur. Sefere katılımı artırmak için yaptığı diğer faaliyetler ise kasabaları gezerek vaazlarda bulunmak ve gidemediği ya da tekrar ulaşmak istediği yerlere davet mektupları yazmaktır. Hayatını konu alan eserlerde Bernard'ın hangi şehir ya da kasabalara uğradığı ve Alman Kralı Konrad ile görüşerek onu da sefere katılması için nasıl ikna ettiğine ayrıntılarıyla yer verilmektedir. Bu bakımdan Bernard'ın, yaklaşımıyla seferleri savaş olarak anlamlandırdığını söylemek yanlış olmayacaktır.

Dönemin en etkili haberleşme şekli olan mektupları aktif bir şekilde kullanan Bernard, tavsiye ve himaye için de yazarak gerek orduların geçeceği yolları güvenli hale getirmek gerekse kutsal topraklara gidecekleri korumak ve cesaretlendirmek, doğru bir iş yaptıklarını, dini bir otoritenin yanlarında olduğunu hissettirmek istemiştir.

Mektuplardan çıkarılan bir diğer önemli husus ikinci seferin başarısızlığa uğramasından sonra, bölgede yaşayanların, üst düzey yönetici bile olsa, artık güvende olmadıklarına inanmaları ve canlarından endişe etmeleridir. Ayrıca Bernard kendi liderlerini hemen geriye döndükleri ve kutsal topraklarda iyi hiçbir iş yapmadıkları gerekçesiyle eleştirmektedir.

Tapınak Şövalyelerinin kurucularından olan arkadaşı Hugh'un istek mektubuna cevaben yazdığı övgüsü, Orta Çă̆'da Tapınakçılar için yazılmış önemli bir belgedir. Eserin literatüre ya da şövalyelere katkısı bir yana, bizim için önemli olan Müslümanlardan bahsederken kullandığı ifadelerdir.

Bernard'ın mektuplarında kullandığı argümanlar çoğunlukla Kutsal Kitap'tan yapılan alıntılarla desteklenmiştir. Teşbihte hata olmaz düsturunu mu kabul etmiştir bilinmez ancak Doğu'yu düşmanlardan kurtarmaktan bahsederken kutsal toprakları işgal edenler için kullandığı köpek ve domuz benzetmelerinin, Müslümanlar hakkında çok da bilgi sahibi

42 "Siquidem annuntiavit et locutus sum, multiplicati sunt super numerum. Vacuantur urbes et castella, et pene jam non inveniunt quem apprehendant septem mulieres virum unum, adeo ubique viduae vivis remanent viris." No: 247, Mabillon, a.g.e., s. 520-521. 
olmayan dönemin Hıristiyan halkının zihninde bir imaj oluşturduğu söylenebilir. Karanlı̆̆ın hizmetkârları, inançsız, imansız ya da dinsiz kelimeleri kullandığı diğer ifadelerdir.

Orta Çağ, Müslüman-Hıristiyan karşıtlığının en yoğun yaşandığı dönemlerden biridir. Haçlı Seferleri de bunun adeta bir yansımasıdır. Bu dönemde halkın sözüne itibar ettiği kesim din adamlarıdır. Onlardan biri olan ve İkinci Haçlı Seferi döneminde papalık tarafindan görevlendirilen Clairvaux Başrahibi Bernard gerek yazarak gerek bizzat ziyaret ederek sefere daha çok insanın katılmasına katkıda bulunmuştur. Amacına hizmet etmek uğruna, benzetme yoluyla Müslümanlar için kullandığı ifadeler de döneme ait Müslüman-Hıristiyan karşıtlı̆̆ının göstergesi niteliğindedir.

Hakem Değerlendirmesi: Dış bağımsız.

Çıkar Çatışması: Yazar çıkar çatışması bildirmemiştir.

Finansal Destek: Yazar bu çalışma için finansal destek almadığını beyan etmiştir.

Peer-review: Externally peer-reviewed.

Conflict of Interest: The author has no conflict of interest to declare.

Grant Support: The author declared that this study has received no financial support.

\section{Kaynakça/References}

Altan, Ebru, İkinci Haçlı Seferi, TTK, Ankara 2003.

Annales Aquenses, ed. M. G. Pertz, MGH, SS XVI, Hannover 1859.

Annales Brunwilarenses, ed. M. G. Pertz, MGH, SS XVI, Hannover 1859.

Annales Remenses et Colonienses, ed. M. G. Pertz, MGH, SS XVI, Hannover 1859.

Annales Rodenses, ed. M. G. Pertz, MGH, SS XVI, Hannover 1859.

Annales S. Iacobi Leodiensis, ed. M. G. Pertz, MGH, SS XVI, Hannover 1859.

Annales Stederburgenses, ed. M. G. Pertz, MGH, SS XVI, Hannover 1859.

Bernardus Claraevallensis Abbas Epistolae, Epistolae Appendix, ed. J. P. Migne, Patrologia Latina, vol. 182, Montrouge 1854.

Bredero, Adrian H., Bernard of Clairvaux, Wm. B. Eerdmans Publishing, 1996.

Codex Diplomaticus et Epistolaris Moraviae, ed. Antonin Bocek, vol. I, Olomucii 1836.

Eugenii III Romani Pontificis Epistolae et Privilegia, ed. J. P. Migne, , Montrouge 1855.

Evans, G. R., Bernard of Clairvaux, Oxford University Press, 2000.

Gazzoli, Marlow, "St. Bernard and The Theology of Crusades", https://thejosias.com/2015/03/17/st-bernardand-the-theology-of-crusade/16.01.2018.

Ghunaimi, Mohammad T., The Muslim Conception of International Law and the Western Approach, Martinus Nijhoff/The Hague, 1968. 
Glick, Thomas F., Islamic and Christian Spain in the Early Middle Ages, BRILL, 2005.

Hıdır, Özcan, Batı’da Hz. Muhammed İmajı, İnsan Yayınları, İstanbul 2019.

Kaschewsky, Rudolf, "The Image of Tibet in the West Before the Nineteenth Century", Imagining Tibet, ed. T. Dodin, H. Räther, Wisdom Publications, 2001.

Kostick, Conor, "Social Unrest and the Failure of Conrad III's March Through Anatolia, 1147”, German History, XXVIII/2, Oxford University Press, 2010.

McGuire, Brian P., "Bernard's Life and Works: A Review", A Companion to Bernard of Clairvaux, ed. B. P. McGuire, BRILL, 2011.

Merton, Thomas, The Last of the Fathers, A Harvest Book, 1882.

Philips, Jonathan, The Second Crusade, Yale University Press, London 2007.

Porter, J. M. B., "Bernard of Clairvaux and the Foundation of the Monastery of Clairvaux (1115)", Great Events in Religion, vol. 1, Ed. F. Curta, A. Holt, ABC-Clio, CA 2017.

Reynolds, Burnam W., The Prehistory of the Crusades, Bloomsbury Publishing, 2016.

Sancti Bernardi, De Laude Novae Militiae, ed. C. D. Mabillon, cap. I, Opera Omnia, Tomus I-II, Paris 1839.

Wynn, Watkin W., Saint Bernard of Clairvaux, Manchester University Press, 1935. 
